\title{
Implementasi Sistem Penyiaran Musik Digital di Kafe menggunakan Visible Light Communication
}

\section{DENNY DARLIS ${ }^{1}$, ARSYAD RAMADHAN DARLIS ${ }^{2}$, MUHAMMAD HIDAYAT ABIBI $^{3}$}

\author{
1,3D3 Teknik Telekomunikasi Universitas Telkom \\ ${ }^{2}$ Teknik Elektro Institut Teknologi Nasional \\ Email: dennydarlis@telkomuniversity.ac.id
}

\begin{abstract}
ABSTRAK
Teknologi penyiaran dengan frekuensi radio menggunakan teknik modulasi frekuensi (FM) telah dikenal sejak lama. Teknologi ini memfasilitasi pengiriman suara melalui sinyal analog dari pemancar kepada penerima. Pengembangan teknologi komunikasi menggunakan cahaya tampak yang memanfaatkan lampu LED sebagai pengirim informasi cukup banyak dilakukan. Pada penelitian ini diimplementasi sistem pengiriman dan penerimaaan siaran musik digital dengan memanfaatkan cahaya tampak yang berasal dari lampu penerangan di kafe. Sistem visible light communication (VLC) diimplementasikan dengan menggunakan metoda modulasi intensitas dan deteksi langsung (IM/DD). Dari hasil pengujian dapat ditunjukkan bahwa sistem ini dapat melewatkan siaran musik digital dengan redaman rata-rata 7,77 dB pada jarak maksimal adalah 3 meter. Hasil dari sistem yang telah dirancang dan diimplementasikan menunjukan hasil yang baik sehingga layak untuk diterapkan pada system penyiaran musik digital di kafe.
\end{abstract}

Kata kunci: Visible Light Communication, IM/DD, Sistem Penyiaran Musik Digital, Sistem Penerangan Kafe.

\begin{abstract}
Broadcasting technology uses radio frequency and technique of frequency modulation (FM) has been known for a long time. This technology allows the transmission of voice through analog signals from transmitter to receiver. Currently, many research on visible light communication technology utilizes LED lights as the sender. In this paper presented the results of transmitter and receiver system implementation of digital musik broadcast for use in the cafe. Visible light communication (VLC) system is implemented using intensity modulation and direct detection (IM/DD) method. From the test results can be shown that this system can pass digital musik broadcast with an average attenuation of $7.77 d B$ at maximum distance is 3 meters. Results of the system that has been designed and implemented shows good results, so it deserves to be applied to the digital musik broadcasting system in the cafe.
\end{abstract}

Keywords: Visible Light Communication, IM/DD, Radio Broadcasting, Café Lighting. 


\section{PENDAHULUAN}

Penggunaan teknologi penyiaran menggunakan frekuensi radio telah dilakukan sejak lama. Salah satu model pengiriman sinyal yang banyak digunakan adalah dengan spektrum frekuensi radio atau nirkabel yang menggunakan gelombang elektromagnetik. Transmisi menggunakan radio dinilai efektif dan efisien akan tetapi banyak kekurangannya antara lain alokasi jangkauan frekuensi yang digunakan untuk beberapa aplikasi sangatlah terbatas, contohnya siaran radio FM yang menggunakan pita 88-108 Mhz, disamping itu biaya dalam izin frekuensi di Indonesia relatif mahal. Dalam hal penerimaan, siaran radio FM lebih banyak dipilih karena kualitas suaranya yang jernih dibandingkan dengan siaran yang menggunakan frekuensi radio lainnya seperti AM dan SW. Namun, muncul masalah yang timbul akibat penggunaan gelombang elektromagnetik contohnya pada kabin pesawat, SPBU, dan rumah sakit, di mana frekuensi radio tidak diperbolehkan karena dapat mengganggu peralatan yang ada tempat tersebut. Salah satu cara agar siaran radio masih dapat dinikmati adalah dengan pengiriman melalui cahaya tampak (Visible Light). Implementasi alat pengirim informasi, khususnya sinyal audio, menggunakan sistem Visible Light Communication (VLC) belum banyak dilakukan. Sementara penerangan menggunakan lampu LED telah lama digunakan dan diperkirakan akan menggantikan seluruh sistem penerangan dalam beberapa tahun ke depan, termasuk penggunaan di Kafe atau area publik yang menyediakan penerangan terusmenerus.

Terdapat beberapa penelitian yang telah dipulikasikan di bidang Visible light communication, diantaranya adalah oleh Arsyad (Darlis, dkk, 2013) dengan judul implementasi visible light communication (VLC) pada sistem komunikasi, dimana sistem VLC telah dapat diimplementasikan dengan baik pada jarak pengiriman sinyal audio sebesar 2,5 m dengan range frekuensi $600 \mathrm{~Hz}$ sampai dengan $45 \mathrm{kHz}$. Sedangkan penelitian dari Gusti (Rinaldi, dkk, 2014) menunjukan sinyal audio dapat dilewatkan dengan baik dengan jarak maksimal 5 meter. Dengan semakin berkembangnya teknologi ini, sinyal video telah dapat dikirim dengan baik, yang ditunjukan oleh Yulian (Yulian, dkk, 2015) dan Arsyad (Darlis, dkk, 2014). Rancangan penguat untuk pengirim dan penerima VLC yang diteliti oleh Ma'ruf (Ma'ruf, dkk, 2015) menunjukkan performansi pengiriman audio yang cukup baik. Pengaruh non-linearitas LED pada system FM-VLC juga telah dipublikasikan oleh Haiyu Zhang (Zhang, dkk, 2015). Berdasarkan beberapa publikasi tersebut, pada penelitian ini akan dilakukan Implementasi sistem penerimaan siaran radio frequency modulation (FM) di kafe menggunakan Visible Light Communication.

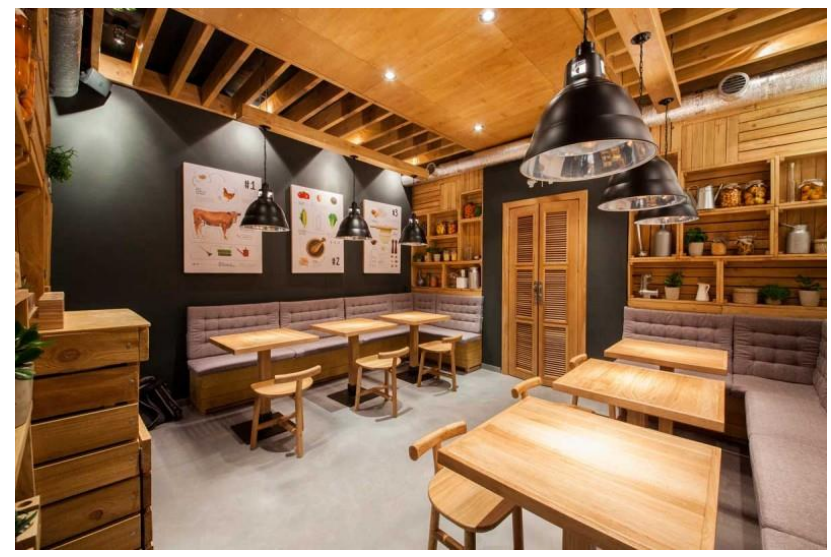

Gambar 1. Sistem Penerangan di Kafe 


\section{METODOLOGI PENELITIAN}

\subsection{Perancangan Sistem}

Pada Gambar 1, ditunjukkan sistem penerangan secara umum yang digunakan di kafe atau area sejenis menggunakan lampu penerangan standar. Dalam penelitian ini diasumsikan bahwa lampu yang digunakan adalah susunan lampu LED untuk setiap meja yang memenuhi standar penerangan ruangan di setiap meja kafe. Dengan susunan lampu penerangan tersebut system pengiriman dan penerimaan siaran musik digital dirancang sedemikian rupa sehingga pengguna yang menggunakan perangkat penerima yang dilengkapi dengan photodiode dapat menerima siaran tersebut dalam lingkup penerangan di masing-masing meja.

Prinsip kerja pemancar dan penerima sinyal audio melalui cahaya lampu ini adalah input data berupa suara yang berasal dari perangkat mp3 player. Secara umum, prinsip kerja perancangan dan realisasi alat pemancar dan penerima audio melalui cahaya tampak dapat digambarkan melalui blok diagram sebagai berikut:

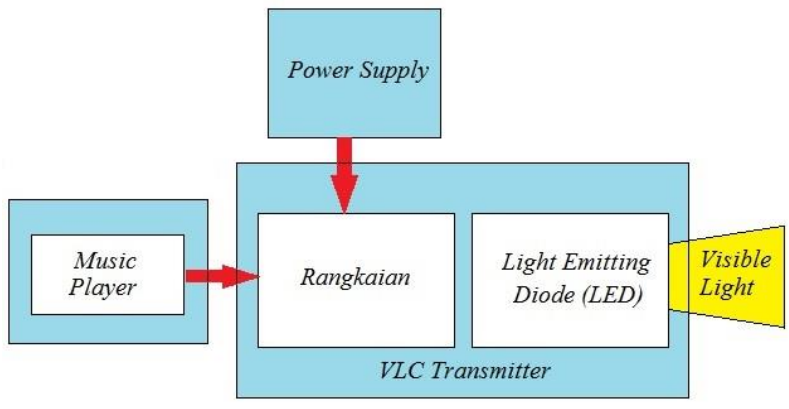

(a)

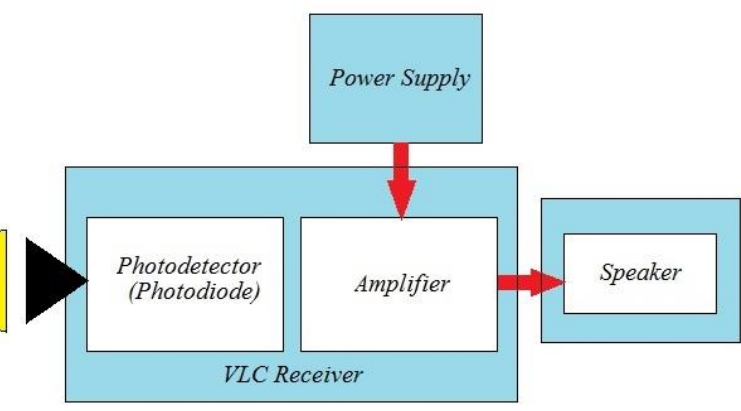

(b)

Gambar 2. Blok Diagram Sistem Visible Light Communication (VLC)

(a) Transmitter (b) Receiver

Blok diagram sistem (Gambar 2) yang telah dirancang dan diimplementasikan secara umum, dibagi menjadi dua bagian, yaitu bagian Transmitter dan Receiver. Sinyal informasi yang akan dikirim dan diterima oleh sistem yang diimplementasikan adalah sinyal audio yang dihasilkan dari $m p 3$ player. Sinyal informasi berupa frekuensi yang dibangkitkan dari $m p 3$ player tersebut akan masuk ke dalam sistem transmitter dan dikuatkan sekaligus dikonversi dari arus menjadi tegangan menggunakan rangkaian yang telah ditentukan sebelumnya. Pada blok ini pula, arus yang masukan akan diubah menjadi tegangan karena berfungsi sebagai current to voltage converter dan sebaliknya, sekaligus menyesuaikan impedansi input dan output agar sistem optimal. Penguatan dilakukan untuk mengantisipasi redaman yang ditimbulkan oleh rangkaian elektronika pada blok selanjutnya dan juga media transmisi yang digunakan yaitu media cahaya tampak yang dihasilkan oleh LED.

Sinyal keluaran dari blok amplifier tesebut akan mengalami proses transformasi dari sinyal listrik menjadi cahaya dengan menggunakan komponen Light Emiting Diode (LED) sehingga dapat ditransmisikan. LED berfungsi untuk mengubah energi listrik menjadi cahaya dengan menggunakan prinsip diode. Jenis LED yang digunakan disini merupakan komponen khusus yang biasa digunakan sebagai penerangan karena berdasarkan tujuan dari penelitian ini adalah memanfaatkan cahaya tampak yang dihasilkan oleh lampu penerangan dalam sistem komunikasi antar perangkat. Cahaya yang mengandung informasi bit tersebut akan ditransmisikan melalui media cahaya (nirkabel) dan diterima oleh perangkat receiver.

Cahaya tersebut akan ditransformasikan oleh perangkat yang berfungsi untuk mentransformasikan cahaya ke sinyal listrik. Perangkat tersebut adalah photosensor. 
Photosensor menyimpan energi cahaya yang diterima, dan mengubahnya menjadi energi listrik. Jenis - jenis photosensor terdapat beberapa jenis yaitu phototransistor, photodiode, solar panel, dan LDR. Pada penelitian ini akan dibandingkan kinerja apabila sinyal audio yang diterima menggunakan photodioda untuk menerima informasi yang dikirimkan.

Sinyal informasi yang diterima oleh photosensor mengalami pelemahan tegangan dibandingkan sinyal yang dikirimkan. Oleh karena itu, diperlukan sebuah penguat tegangan (Amplifier). Stereo Amplifier digunakan dalam melakukan proses tersebut. Sinyal yang telah dikuatkan akan diproses pada rangkaian yang akan mengubah sinyal listrik menjadi sinyal suara. Display yang digunakan berupa speaker untuk menampilkan sinyal audio berupa sinyal yang dikirimkan oleh transmitter. Dengan display ini akan terlihat batasan banyaknya sinyal yang mampu ditunjukan oleh sistem.

Dalam hal ini proses lebih mendalam akan dijelaskan secara terperinci fungsi dari tiap komponennya, dimulai dari input sinyal audio lalu dikuatkan agar dapat ditransmisikan menggunakan LED yang mengubah sinyal listrik menjadi cahaya sehingga dapat terjadinya modulasi pada cahaya LED yang terpancar. Lalu, diterima oleh photodioda yang mengubah sinyal cahaya menjadi sinyal listrik. Setelah menjadi sinyal listrik, informasi yang diterima masuk kebagian penguatan (Amplifier) menggunakan Transistor BC547 frekuensi rendah lalu diteruskan ke speaker.

Fungsi dari masing-masing blok akan dijelaskan lebih mendalam pada tiap bagian pada blok diagram rangkaian diatas adalah sebagai berikut:

1. Lampu LED berfungsi untuk sumber cahaya dan sebagai transmitter. Lampu light Emiting Diode atau yang biasa disebut lampu LED adalah lampu penerangan yang berbentuk solid tanpa adanya gas maupun zat - zat kimia yang dapat memancarkan cahaya. Dengan menggunakan lampu penerangan LED diyakini mengeluarkan panas yang lebih sedikit dibandingkan dengan lampu bohlam.Dikarenakan fungsi led adalah pengubah elektrik menjadi cahaya maka dapat disebut juga sebagai modulasi cahaya. Modulasi dapat diartikan suatu teknik dalam telekomunikasi dengan menumpangkan sebuah sinyal kepada sinyal asal. Sinyal asal disini dapat diterjemahkan sebagai sinyal asli yang membawa pesan informasi (data), dapat pula disebut sebagai sinyal data. Sinyal yang ditumpangkan ini kemudian dikenal dengan sinyal pemodulasi. Sinyal pemodulasi ini haruslah memiliki nilai amplitude yang lebih tinggi dibandingkan sinyal awal, hal ini disebabkan jika sinyal pemodulasi tidak memiliki frekuensi lebih tinggi maka modualsi yang dihasilkan tidak sempurna. Pada modulasi, teknik banyak digunakan dalam mentransmisikan sebuah sinyal data untuk jarak yang cukup jauh atau dekat, pemakaian teknik didasari akan kemudahah dalam mengolah sinyal dimodulasi dengan pemodulasi serta dapat diamati prosesnya secara langsung.

2. Detektor Cahaya (photodioda) berfungsi untuk pengubah sinyal cahaya menjadi besaran listrik dan sebagai penerima data,pada blok ini Penggunaan detektor, pada gelombang cahaya dipakai dalam mendeteksi adanya sinyal gelombang cahaya yang dikirimkan oleh pemancar (transmitter), detektor yang biasa digunakan pada gelombang cahaya ialah photodioda. Kedua detektor cocok digunakan dalam demodulasi bersifar mekanik. Photodioda digunakan dalam penelitian ini, disebabkan detektor lebih sensitif terhadap sumber cahaya yang datang kepadanya serta dengan suhu konduktor yang relatif baik, sehingga penggunaan photodioda dianggap cocok. Prinsip kerja dari photodioda merupakan kebalikan dari cara kerja LED, saat sumber cahaya ditangkap oleh photodioda maka sumber cahaya yang berupa foton-foton cahaya tadi diubah menjadi electron yang kemudian akan menjadi arus listrik akibat elektromagnetik. Sehingga besaran sinyal termodulasi akan terbaca dalam satuan volt dengan domain waktu. 
Demodulasi berfungsi untuk mengubah cahaya yang membawa informasi menjadi sinyal informasi elektrik atau disebut juga teknik rekonstruksi ulang sinyal yang termodulasi ke bentuk asal sinyal, proses ini merupakan kebalikan daripada teknik modulasi. Pada demodulasi sinyal cahaya yang termodulasi akan diterima oleh sebuah penerima, yang disebut detektor. Detektor inilah yang kemudian bertugas untuk mendeteksi sinyal yang dikirimkan (termodulasi) untuk selanjutnya didemodulasi.

3. Amplifier rangkaian komponen elektronika yang dipakai untuk menguatkan daya (atau tenaga secara umum). Dalam bidang audio, amplifier akan menguatkan signal suara yaitu memperkuat signal arus (I) dan tegangan (V) listrik dari inputnya menjadi arus listrik dan tengangan yang lebih besar (daya lebih besar) pada bagian outputnya.

4. Input data digunakan untuk masukan data berupa suara dari output mp3 player.

5. Output data digunakan untuk keluaran data berupa suara ke speaker.

\subsection{Implementasi Sistem Transmitter}

\subsubsection{Sumber Pemancar}

Sumber informasi yang dihasilkan dari suara manusia berupa frekuensi audio yang mempunyai sifat sinusoidal dengan karakteristik bandwidth frekuensi $20 \mathrm{~Hz}$ sampai dengan $20.000 \mathrm{~Hz}$ untuk ditransmisikan, sumber suara sendiri memiliki spesifikasi dalam melakukan perancangan alat yang akan dipenuhi sebagai berikut:
a. Respon frekuensi manusia
: $20 \mathrm{~Hz}-20.000 \mathrm{~Hz}$
b. Sumber Daya
: Baterai $9 \mathrm{~V}$
c. LED
d. Resistor
: White Superbright
e. Kapasitor
: 100 ohm, 75 ohm
f. Konektor
: $330 \mathrm{pF}, 330 \mathrm{nF}$
: jack audio $3 \mathrm{~mm}$

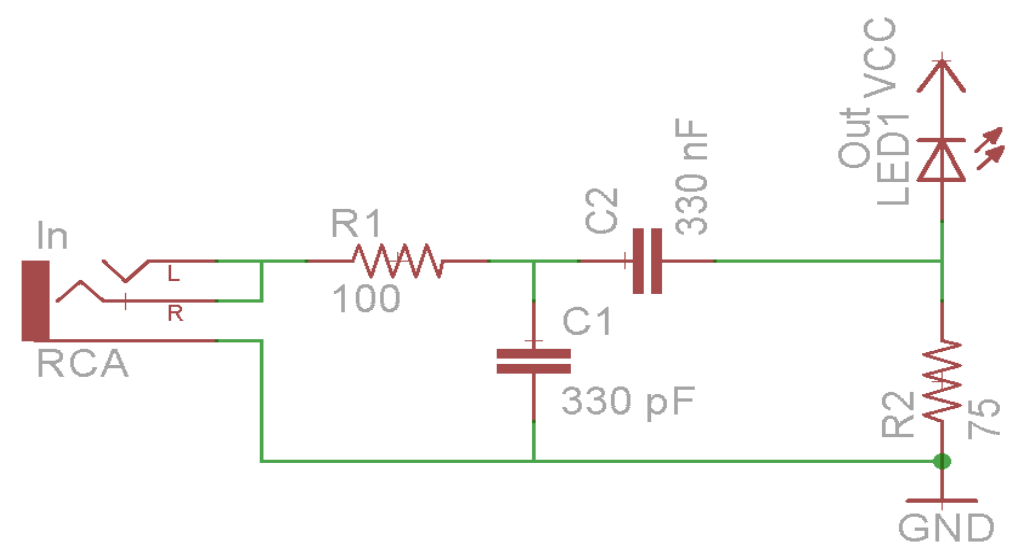

Gambar 3. Rangkaian Transmitter

Gambar 3 menunjukkan rangkaian pengirim (Transmitter) yang digunakan pada penelitian ini. Sinyal audio yang masuk mellaui jack audio $3 \mathrm{~mm}$ akan ditapis mengunakan rangkaian penapis audio dan digunakan untuk memodulasi intensitas LED.

\subsubsection{Spesifikasi LED}

LED yang digunakan dalam penelitian ini adalah LED SMD-Superbright yang mempunyai spesifikasi sebagai berikut :
a. Temperatur operasi
$=-40 \mathrm{C}$ sampai dengan $+105^{\circ} \mathrm{C}$
b. Arus forward ( IF )
$=350 \mathrm{~mA}$
c. Tegangan forward bias
$=7.5 \mathrm{~V}$
d. Respon Frekuensi LED Superbright 
Cahaya dihasilkan dari LED digunakan sebagai pembawa informasi sebagai media transmisi yang digunakan dalam penelitian ini. Perubahan intensitas cahaya LED sangat tergantung dari perubahan arus DC yang mengalir dalam LED, maka dari itu dibutuhkan rangkaian LED Driver. Gamabr 4 menunjukkan hasil implementasi rangkaian pengirim dengan menggunakan 6 buah LED yang disusun secara paralel.

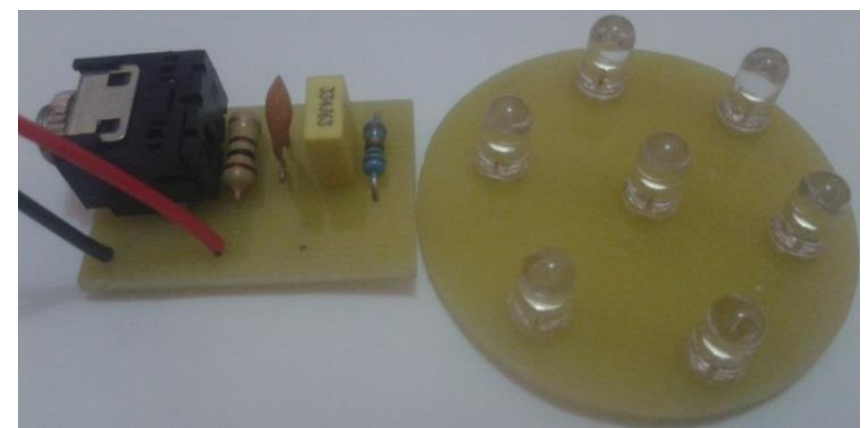

Gambar 4. Hasil Implementasi Transmitter

\subsection{Implementasi Sistem Receiver}

Sinyal suara yang dikirimkan oleh Transmitter akan diterima oleh photodioda yang akan mengubah sinyal cahaya menjadi sinyal listrik (Gambar 5). Setelah itu sinyal suara masuk ke blok penguat. Kemudian dapat teruskan ke speaker sampai terdengar telinga manusia.

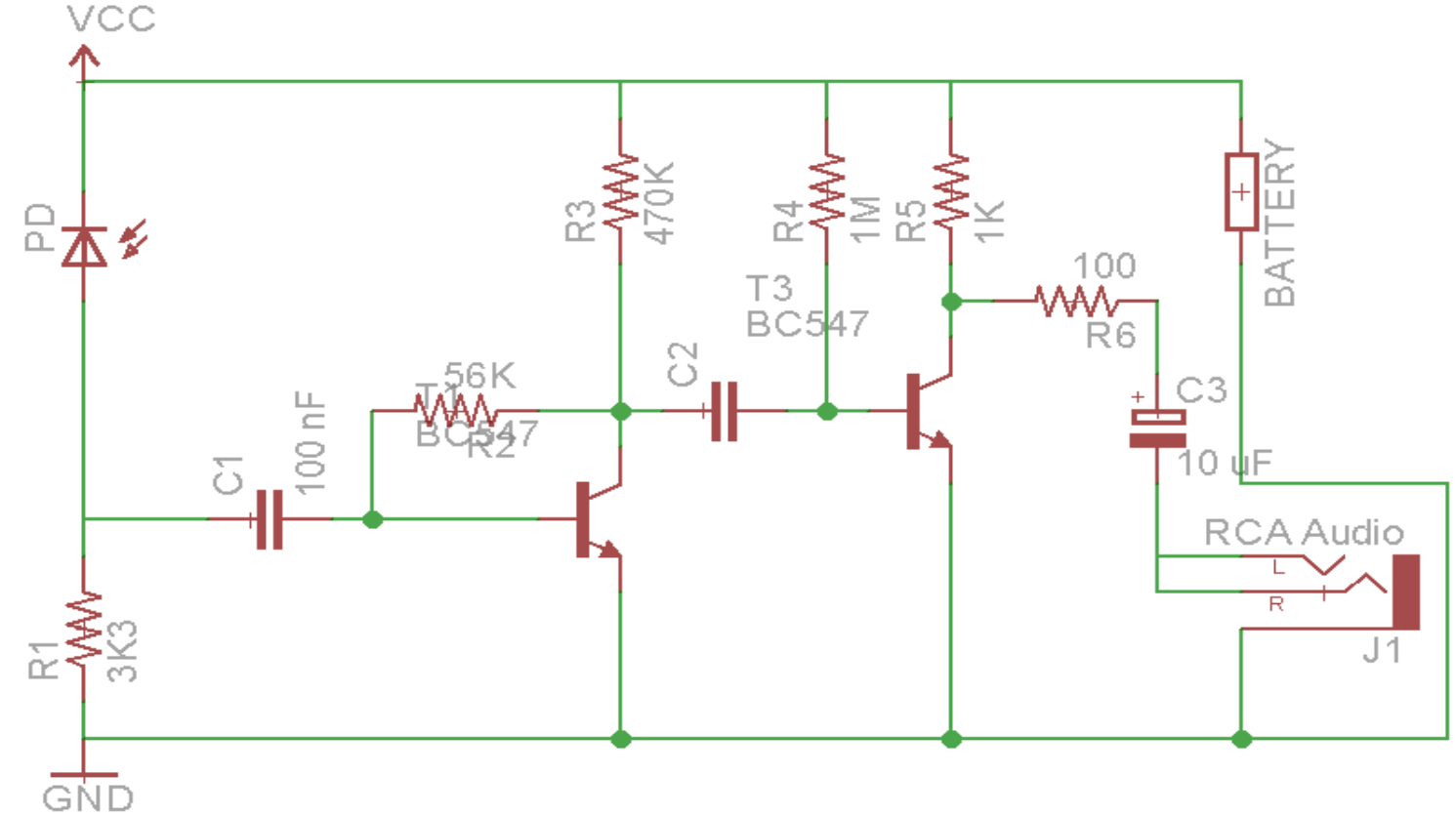

Gambar 5. Rangkaian Receiver

\subsubsection{Spesifikasi Photodioda}

Sinyal cahaya yang diubah photodioda menjadi arus listrik yang besarnya sebanding dengan daya cahaya yang diterima. Timbulnya arus listrik menyebabkan adanya tegangan yang melintasi beban R3. Karena tegangan yang melintasi beban besarnya dalam orde beberapa mVolt, maka diperlukan penguatan. 


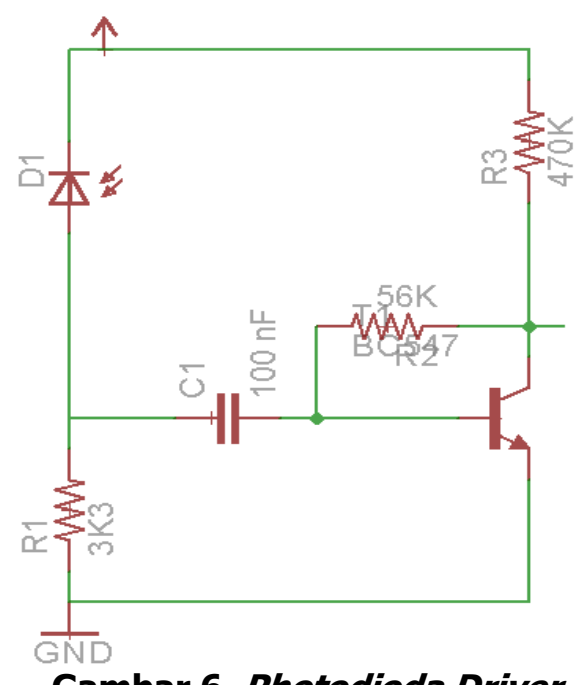

Proses yang terjadi pada Gambar 6, photodioda menerima cahaya, sehingga basis transistor mendapat bias tegangan dan transistor ON dimana terminal output diambil pada terminal kolektor transistor sehingga terminal output dihubungkan ke ground oleh transistor melalui emitornya. Begitu sebaliknya pada saat photodioda tidak menerima cahaya maka basis transistor tidak mendapat bias sehingga transistor berhenti beroperasi dan terminal output mendapat sumber tegangan dari $\mathrm{V}_{\mathrm{cc}}$.

\subsubsection{Amplifier Penerima}

Setelah photodioda mendapat logika operasi dalam mengubah sinyal cahaya menjadi sinyal listrik, maka proses selanjutnya yaitu sinyal listrik diteruskan ke rangkaian penguat sebelum diubah menjadi sinyal suara oleh speaker seperti ditunjukkan pada Gambar 7.

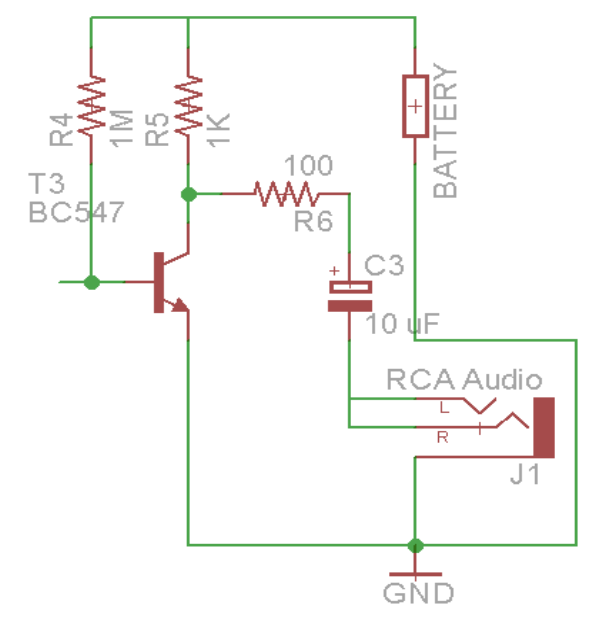

\section{Gambar 7. Rangkaian Penguat Receiver}

Sinyal cahaya yang telah diterima oleh photodioda dan telah diubah menjadi sinyal listrik akan teruskan ke rangkaian penguat menggunakan Transistor BC547 frekuensi rendah lalu di teruskan menuju speaker untuk diubah menjadi suara. Bagian penerima yang telah diimplementasikan secara elektronika ditunjukkan pada Gambar 8 dengan menggunakan 9 photodioda yang disusun secara paralel. Hal ini bertujuan untuk meningkatkan arus yang diubah dari hasil penerimaan cahaya dari pengirim. 


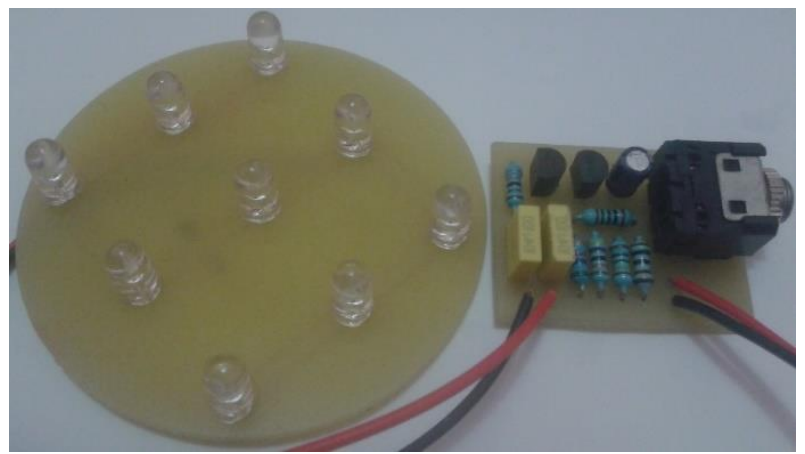

Gambar 8. Hasil Implementasi Receiver

\subsection{Prinsip Kerja Keseluruhan Sistem}

Prinsip kerja sistem dapat dilihat secara keseluruhan yang dimulai dari masukan sinyal audio sampai dengan mendapat keluaran sinyal audio sehingga mampu diubah menjadi suara oleh speaker bertujuan untuk mempermudah pembaca untuk mengetahui alur kerja dari rangkaian yang telah dibuat. Sinyal suara diterima oleh RCA Audio Input, dikuatkan untuk kemudian dikirimkan melalui LED. Perbedaan tegangan antara anoda yang stabil dan katoda yang tidak stabil atau berubah-ubah sesuai dengan tegangan informasi akan menyebabkan LED berkedip (kadang-kadang) namun pada frekuensi tinggi pada aliran musik tertentu dapat membuat LED tidak berkedip sama sekali. Pancaran cahaya LED tersebut yang akan diterima oleh 9 photodioda untuk diubah menjadi sinyal listrik. Kemudian sinyal tersebut dikuatkan kembali menggunakan Transistor BC547 lalu sinyal tersebut dikeluarkan melalui RCA Audio Output untuk selanjutnya di-Play di speaker berupa suara yang terdengar telinga manusia.

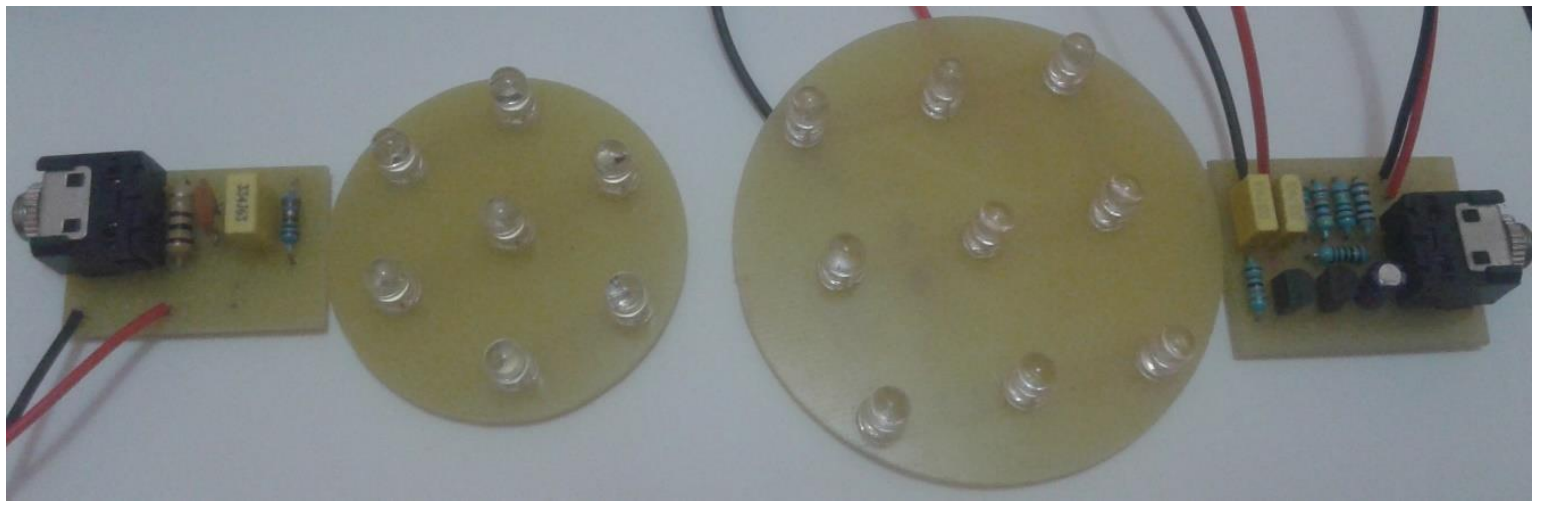

Gambar 9. Perangkat Transmitter dan Receiver

Gambar 9 menunjukan merupakan perangkat yang telah dibuat dan dicetak dengan rapi, proses selanjutnya yaitu merancang model atau bentuk yang akan menjadi posisi dan tempat perangkat. Penggambaran posisi dan bentuk perangkat yang telah dibuat berguna untuk menjelaskan penggunaan perangkat sebelum diimplementasikan pada Kafe.

\subsection{Model Penerapan Sistem}

Pada model penerapan perangkat, digambarkan dengan implementasi sesuai rencana yang diharapkan untuk sistem yang telah dibuat agar pembaca pengetahui penggunaan sistem yang telah dirancang apabila akan diterapkan pada suatu ruangan di sebuah Kafe dengan perangkat yang menggunakan sistem tersebut, dengan ilustrasi seperti ditunjukan pada Gambar 10. sebagai berikut: 


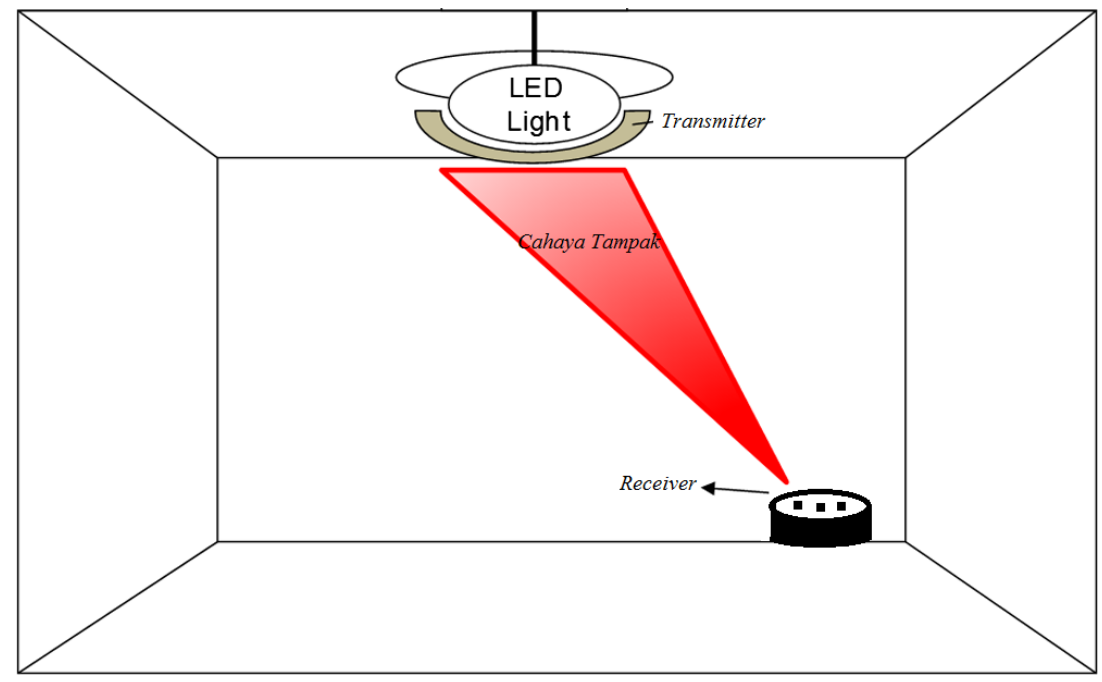

Gambar 10. Model Penerapan Sistem

\section{HASIL DAN PEMBAHASAN}

\subsection{Pengujian Transmitter}

Pengujian pada blok transmitter diuji dengan oscilloscope untuk mengetahui keterangan sinyal audio yang berupa analog. Dengan menggunakan frekunsi $20-20.000 \mathrm{~Hz}$ dilakukan pengiriman sinyal audio untuk melihat kinerja pada perangkat Transmitter dengan membandingkan hasil keluaran sebelum di modulasikan menggunakan LED sama dengan sinyal masukan dari Signal Generator. Pengujian blok transmitter yang akan di uji yaitu rangkaian Transmitter. Setelah pengambilan data selanjutnya dapat dibuat grafik untuk menunjukan pengaruh yang signifikan berdasarkan dari frekuensi yang melewati perangkat Transmitter. Gambar 11 menunjukan respon frekuensi pada transmitter. Pada Gambar 11 terlihat adanya atenuasi atau pelemahan daya terima yang direspon oleh Receiver. Dari hasil pengukuran, sistem ini mampu melewatkan frekuensi $20-20.000 \mathrm{~Hz}$ dengan rata-rata Atenuasi $7,77 \mathrm{~dB}$.

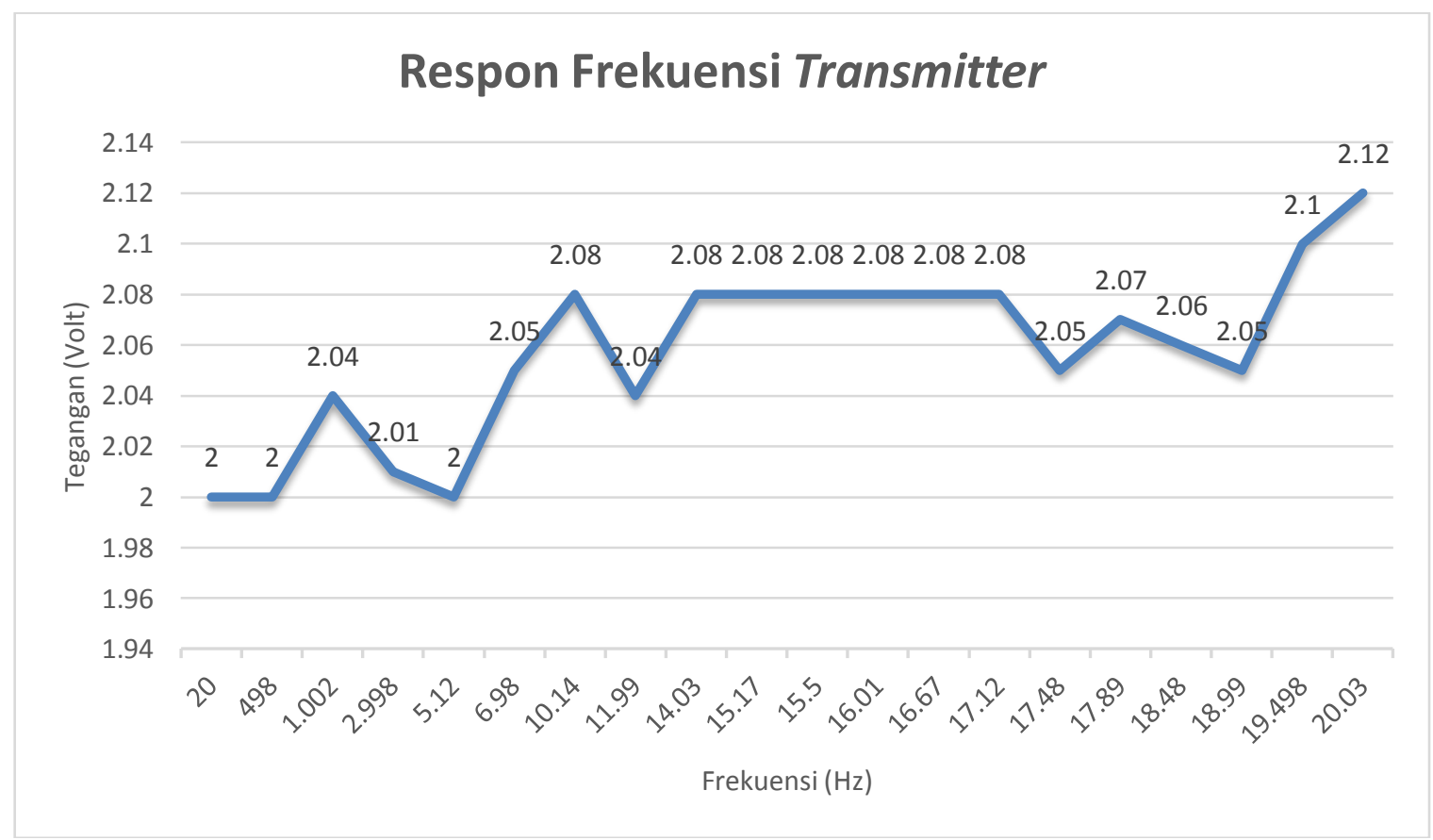

Gambar 11. Grafik Respon Frekuensi Transmitter 
Perbandingan bentuk sinyal dari Signal Generator sama persis seperti keluaran dari sistem. Dengan bentuk sinyal seperti pada Gambar 12.

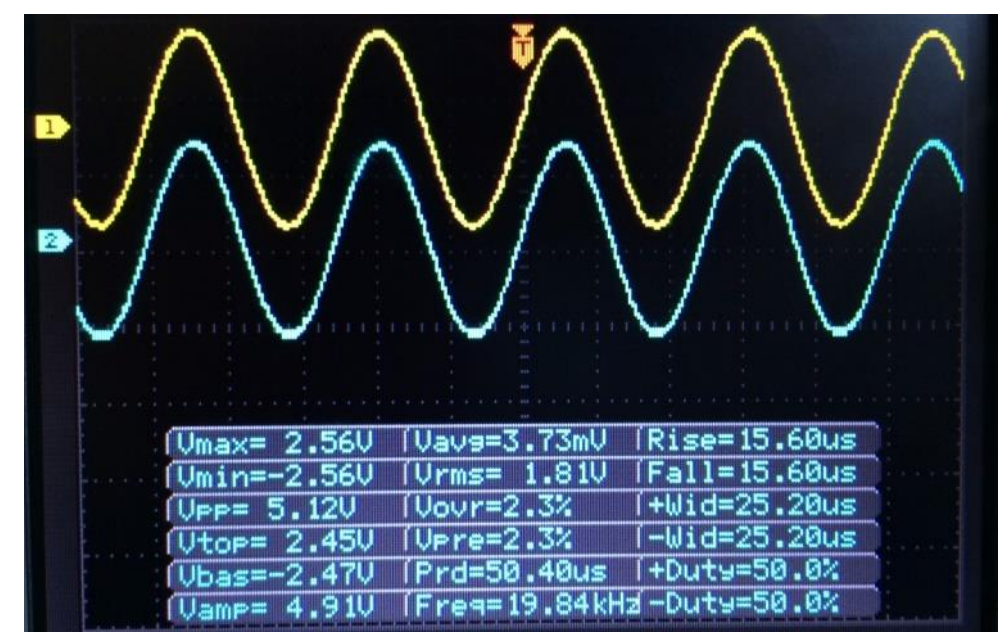

Gambar 12. Bentuk Sinyal Perangkat Transmitter

\subsection{Pengukuran Receiver}

Pengujian pada blok Receiver di uji dengan oscilloscope untuk mengetahui keterangan sinyal audio yang berupa analog seperti ditunjukkan pada Gambar 13. Dengan menggunakan frekunsi $20-20.000 \mathrm{~Hz}$ dilakukan pengiriman sinyal audio untuk melihat kinerja pada perangkat Receiver dengan membandingkan hasil keluaran sebelum di demodulasikan menggunakan photodioda sama dengan sinyal masukan dari Signal Generator. Pengujian blok transmitter yang akan di uji yaitu rangkaian penguat dan rangkaian Photodiode Driver. Setelah pengambilan data, maka selanjutnya bisa dibuat grafik untuk menunjukan pengaruh yang terjadi begitu signifikan berdasarkan dari frekuensi yang melewati perangkat Receiver.

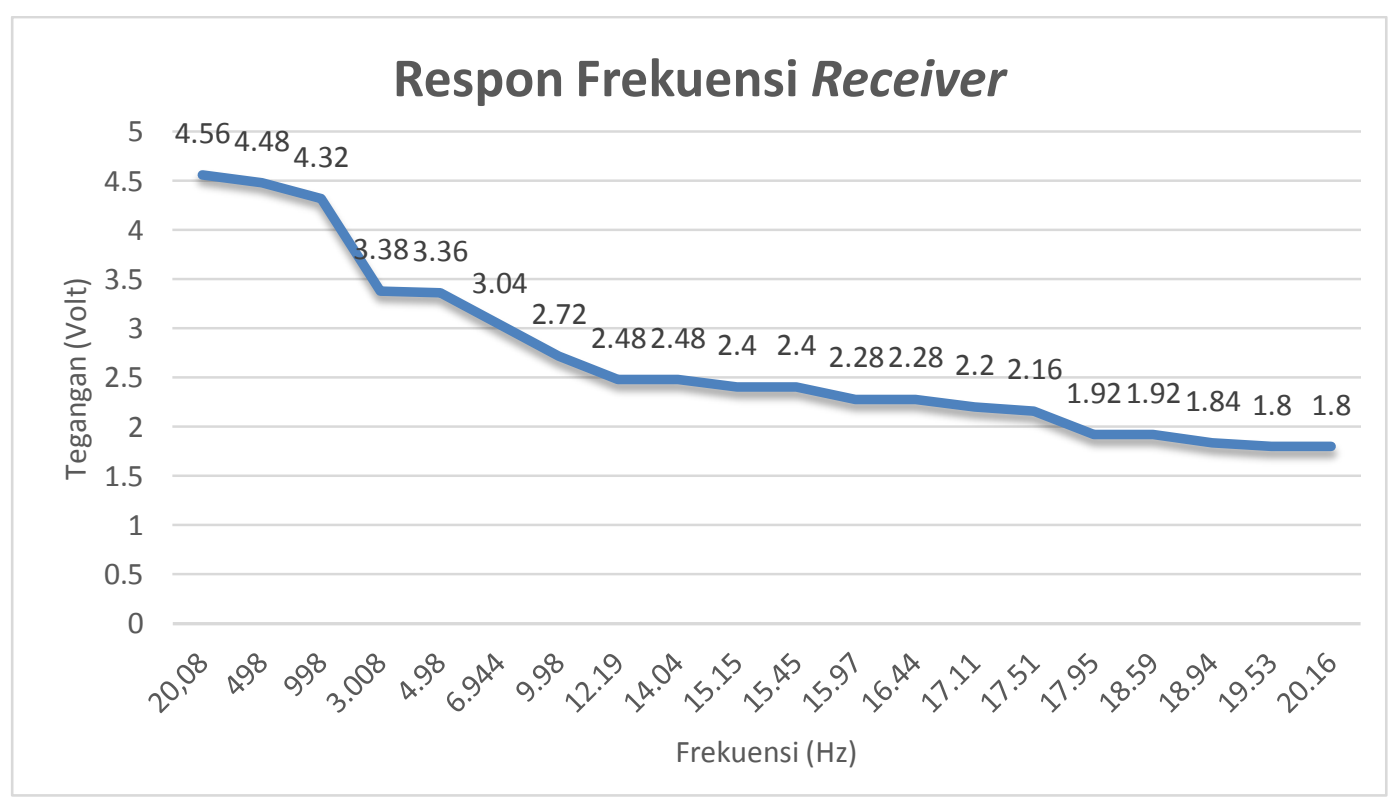

Gambar 13. Grafik Respon Frekuensi Receiver 
Pada sinyal informasi yang digunakan pada frekuensi yang dapat didengarkan oleh telinga manusia terlihat bahwa sistem telah dapat melewatkan frekuensi $20-20.000 \mathrm{~Hz}$. Atenuasi tersebut dipengaruhi terhadap besarnya frekuensi yang melewati sistem, semakin besar frekuensi yang lewat pada sistem maka semakin besar Atenuasi yang terjadi, pengaruh Atenuasi akan berdampak kepada Volume Audio. Apabila melihat pada bentuk sinyal yang ditunjukkan pada Gambar 14 maka dapat disimpulkan sinyal informasi yang masuk kedalam sistem sama dengan sinyal keluaran.

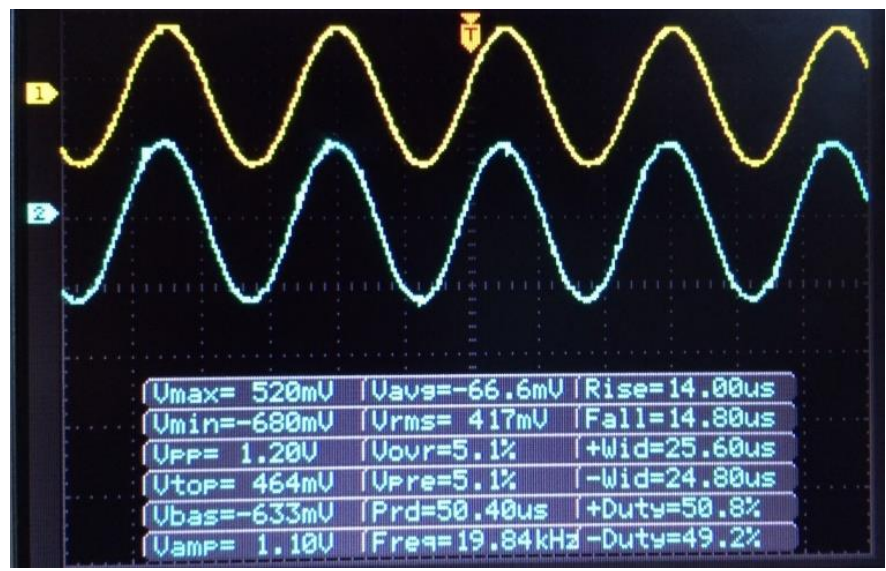

Gambar 14. Bentuk Sinyal Perangkat Receiver

\subsection{Pengujian Transmitter dan Receiver}

Setelah melakukan pengujian terhadap masing-masing perangkat Transmitter dan Receiver untuk mengetahui kinerja alat yang telah dibuat, maka pengujian selanjutnya yaitu mengukur kinerja pada saat Transmitter mengirimkan sinyal informasi dan Receiver menerima sinyal informasi. Untuk membandingkan sinyal yang masuk pada Transmitter serta sinyal yang keluar pada Receiver sebelum masuk ke speaker, dilakukan dalam dua kondisi yaitu terdapat penghalang dan tidak terdapat penghalang diantara Transmitter dan Receiver dengan pengiriman sinyal kontinu.

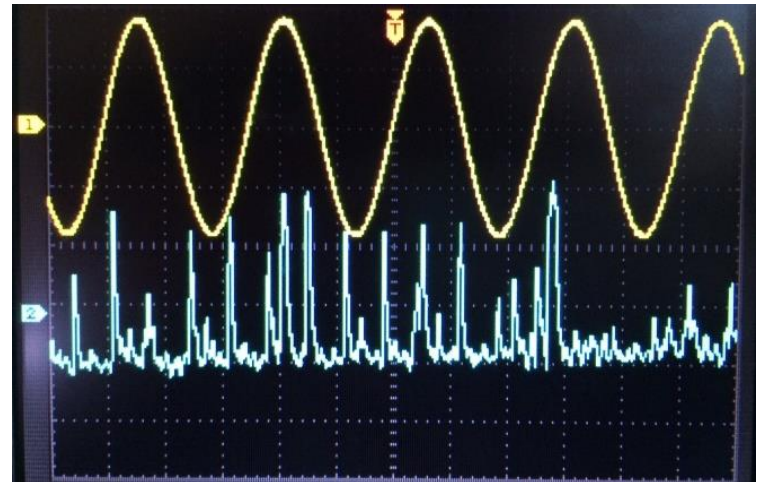

(a)

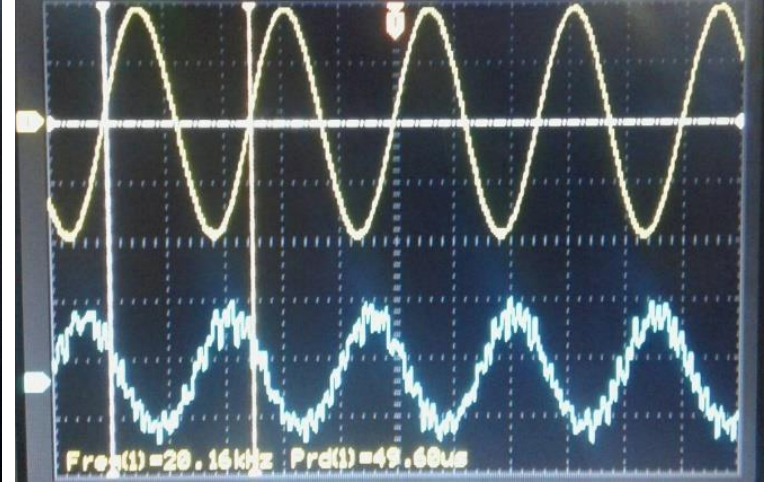

(b)

Gambar 15. Bentuk Sinyal Transmitter dan Receiver

(a) Kondisi dihalangi (b) Kondisi tanpa penghalang

Terlihat pada Gambar 15 (a) bentuk sinyal yang diterima dengan terdapat penghalang (sinyal bawah) memiliki bentuk yang jauh berbeda dengan sinyal yang diterima (sinyal atas), sedangkan pada bentuk sinyal (b) sinyal yang diterima (sinyal atas) mengikuti sinyal yang dikirimkan (sinyal atas), akan tetapi terjadi noise yang mempengaruhi hasil sinyal yang 
diterima Receiver. Pengukuruan selanjutnya mengukur frekuensi maksimal dengan hasil pengukuran pada Gambar 16.

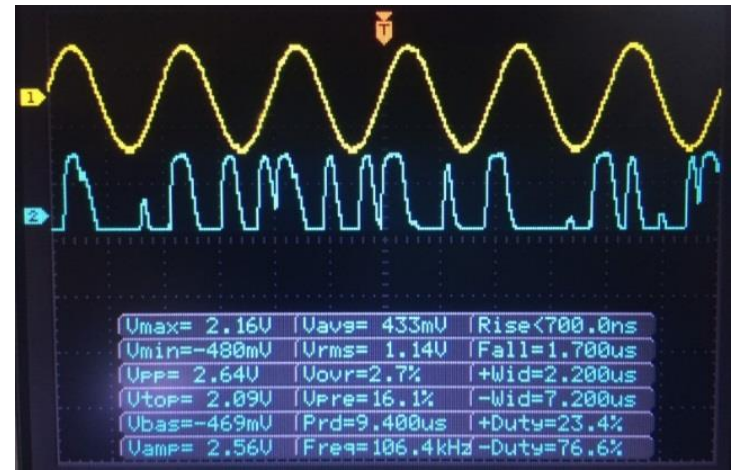

Gambar 16. Frekuensi Maksimal Pengiriman Sinyal Informasi

Setelah mengetahui kinerja perangkat yang telah dibuat mampu melewatkan frekuensi sesuai dengan frekuensi operasi yang diharapkan untuk dapat ditransmisikan, maka selanjutnya dilakukan pengukuran frekuensi maksimal, yang menjadi batas frekuensi dimana perangkat yang telah dibuat sudah tidak beroperasi dalam kinerja yang baik dalam menerima sinyal informasi yang dikirimkan. Hasil yang didapatkan dari pengukuran tersebut terlihat bahwa bentuk sinyal pada frekuensi $106.4 \mathrm{kHz}$ sebelum dikirimkan berbeda dengan frekuensi yang diterima oleh Receiver, berarti dapat disimpulkan bahwa frekuensi yang mampu diterima yaitu kurang dari $106.4 \mathrm{kHz}$.

\subsection{Pengujian Pengiriman Sinyal Audio}

Pengujian dengan kondisi seperti ini menggunakan instrument pengujian yang sedikit berbeda dari pengujian yang telah dilakukan sebelumnya, dimana instrument Signal Generator digantikan dengan mp3 player sebagai sumber informasi yang utama dalam hasil akhir dilakukannya penelitian. Namun, tujuan dari pengukuran ini sama seperti sebelumnya yaitu untuk membandingkan frekuensi audio yang dihasilkan oleh $\mathrm{mp3}$ player dan melalui perangkat Transmitter serta frekuensi audio yang diterima oleh perangkat receiver.

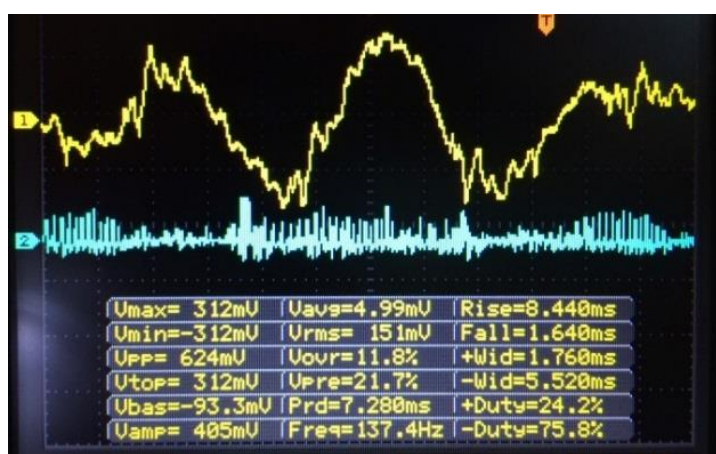

(a)

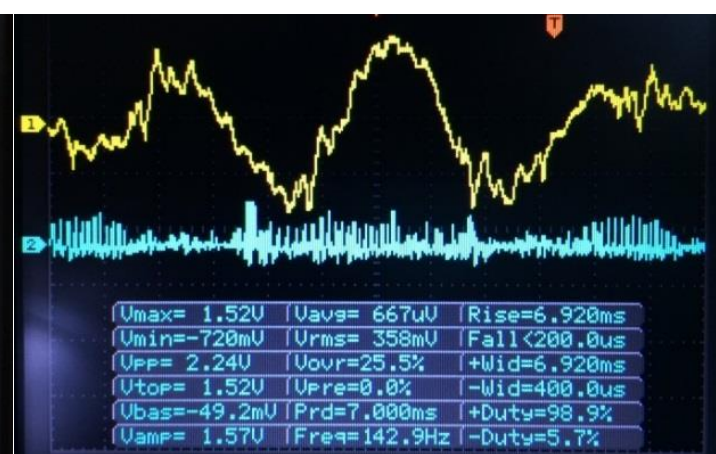

(b)

Gambar 17. Bentuk sinyal dengan sinyal informasi berupa musik (a)Informasi pada sinyal masukan (b)Informasi pada sinyal keluaran

Pada perbandingan indikator pengukuran sinyal yang diterima oleh perangkat Receiver dengan mengukur frekuensi yang dihasilkan dari mp3 Player dengan Genre musik tertentu (Hard Rock), dapat dilihat bahwa perbandingan frekuensi yang dikirimkan (137.4 Hz) pada Gambar 17(a) dengan frekuensi yang diterima $(142.9 \mathrm{~Hz})$ pada Gambar 17 (b) memiliki nilai yang tidak jauh berbeda, serta terjadinya penguatan oleh rangkaian Amplifier pada 
perangkat Receiver yang berguna untuk menambah intensitas suara yang akan dikeluarkan oleh Speaker.

\section{KESIMPULAN}

Dari hasil perancangan, implementasi dan pengujian, maka dapat diambil dari beberapa kesimpulan sebagai berikut:

1. Perangkat Visible Light Communication yang dirancang dan diimplementasikan dapat digunakan untuk mengirim dan menerima siaran musik digital pada jarak maksimal 3 meter.

2. Bagian Transmitter dapat melewatkan frekuensi $20-20.000 \mathrm{~Hz}$ dengan mengalami pelemahan atau atenuasi dengan rata-rata $7.7 \mathrm{~dB}$.

3. Pada Receiver, semakin besar frekuensi yang dilewatkan maka semakin tinggi pelemahan atau atenuasi yang terjadi, dengan frekuensi optimal kurang dari 106.4 $\mathrm{kHz}$.

4. Hasil dari sistem yang telah dirancang dan diimplementasikan menunjukan hasil yang baik sehingga layak untuk diterapkan pada sistem penyiaran musik digital di kafe.

\section{DAFTAR RUJUKAN}

Darlis, A., Lidyawati, L., \& Nataliana, D. (2013). Implementasi Visible Light Communication (VLC) Pada Sistem Komunikasi. Jurnal Elkomika. 1(1): 13 - 25.

Rinaldi, G. I., Darlis, D., \& Putri, H. (2014). Implementasi Visible Light Communication (VLC) Untuk Komunikasi Suara. Proyek Akhir D3 Teknik Telekomunikasi Universitas Telkom.

Yulian, D., Darlis, D., \& Aulia, S. (2015). Perancangan dan Implementasi Perangkat Visible Light Communication Sebagai Transceiver Video. Jurnal Elektronika Telekomunikasi Terapan (JETT). 2(2): $196-206$.

Darlis, A., Lidyawati, L., Jambola, L., \& Wulandari, N. (2014). Implementasi Sistem Komunikasi Video menggunakan Visible Light Communication (VLC). Jurnal Reka elkomika. 2(3): 160 - 173.

Ma'ruf, M. I. , Othman, M. B., \& Pramono, S. H. (2015). Audio transmission using visible light communication. International Conference on Electrical and Electronic Engineering 2015 (IC3E 2015).

Zhang, H., Liu, P., Li, Q., Liu, J., Liu, S. (2015). LED Nonlinearity Impact on Frequency Modulation Signals over Visible Light Communication. 2015 IEEE International Conference on Communication Problem-Solving (ICCP) (pp. 369-372). 